\title{
Vitamin D and Lung Cancer Risk: A Comprehensive Review and Meta-Analysis
}

\author{
Liqun Zhang $^{\mathrm{a}}$ Sihai Wang ${ }^{\mathrm{a}}$ Xiaoyu Che ${ }^{\mathrm{b}}$ Xuehui Lia \\ aDepartment of Respiratory Diseases, Beijing Military Region General Hospital of PLA, Beijing, \\ bDepartment of Respiratory Diseases, Beijing Military Region 266th Hospital of PLA, Chengde, China
}

\author{
Key Words \\ Vitamin D • Lung cancer • Risk
}

\begin{abstract}
Background/Aim: Vitamin D has been suggested to have important roles against cancer development. There were several published studies on the association between vitamin $D$ and lung cancer risk, but not conclusive results were available. Methods: To clarify the role of vitamin $\mathrm{D}$ in lung carcinogenesis, we performed a comprehensive review of the literature and a meta-analysis to evaluate the association of serum vitamin $D$ levels and dietary vitamin $D$ intake with lung cancer risk. Twelve studies (9 prospective cohort and 3 nested case-control studies) with a total of 288,778 individuals were included. The summary relative risk (RR) with 95\% confidence interval (CI) was used to assess lung cancer risk. Results: Meta-analysis of total 12 studies showed that RR for the association of high vitamin D status with lung cancer was 0.84 (95\%CI $0.78-0.90, P<0.001)$. The RR of lung cancer for the highest versus lowest quintile of serum vitamin D levels was 0.83 (95\%CI $0.77-0.90, P<0.001)$. The RR of lung cancer for the highest versus lowest quintile of vitamin $D$ intake was $0.89(95 \% C I 0.74-1.06, P=0.184)$. Conclusion: Current data suggest an inverse association between serum vitamin $D$ and lung cancer risk. Further studies are needed to investigate the effect of vitamin $D$ intake on lung cancer risk and to evaluate whether vitamin D supplementation can prevent lung cancer.
\end{abstract}

Copyright (C) 2015 S. Karger AG, Basel

\section{Introduction}

The role of vitamin D in the bone health has been well known [1]. Recent studies have shown that vitamin $\mathrm{D}$ is an important pro-hormone and has many biological roles in human body $[2,3]$. Vitamin D insufficiency is a global health problem and is associated with a number of illnesses [4,5]. Vitamin $\mathrm{D}$ also has been suggested to have important roles against cancer development, and it has anti-tumor effects [6, 7]. Previous epidemiological

Liqun Zhang, $\mathrm{MD}_{\text {, }}$

KARGER 125
Department of respiratory diseases, Beijing Military Region General Hospital of PLA, NO.5 Nanmencang, Dongcheng District, Beijing 100700 (China)

E-Mail zlqpla@163.com 


\section{Cellular Physiology Cell Physiol Biochem 2015;36:299-305 \\ \begin{tabular}{l|l|l} 
DOI: 10.1159/000374072 & (C) 2015 S. Karger AG, Basel
\end{tabular} \\ \begin{tabular}{l|l} 
and Biochemistry Published online: May 04, 2015 & www.karger.com/cpb
\end{tabular} \\ Zhang et al.: Vitamin D in Lung Tumor}

studies have suggested that vitamin $\mathrm{D}$ is associated with decreased risks of colorectal cancer, and breast cancer $[4,8]$. Findings from vitro studies showed that vitamin D could result in an additive decrease in cell proliferation and the induction of apoptosis in small cell lung carcinoma cell lines $[7,9]$. Other studies found that vitamin D could inhibit the metastatic growth of lung cancer cells in animal models $[6,10]$. Thus, findings from previous studies showed the possible preventive role of vitamin $\mathrm{D}$ against lung cancer. There were also several epidemiological studies assessing the association between vitamin $\mathrm{D}$ and lung cancer risk [11-19]. However, there were not conclusive results available from previous studies. To clarify the role of vitamin D in lung carcinogenesis, we performed a review of the literature and meta-analysis of cohort studies to evaluate the association of serum vitamin D levels and dietary vitamin D intake with lung cancer risk.

\section{Materials and Methods}

\section{Search of papers and inclusion criteria}

A systematic literature search was conducted in PUBMED, EMBASE and Web of Knowledge. We searched all studies published before 20 October, 2014. We used the following combinations of searching terms: (vitamin D, or 25-hydroxyvitamin D) AND (lung cancer, pulmonary cancer, lung carcinoma, or pulmonary carcinoma). There was no language in the literature search. After reviewing the abstracts, studies potentially eligible for inclusion were further assessed by reading full-texts. The reference lists of all eligible studies and relevant reviews were also retrieved to find other eligible studies. Two investigators independently assessed all the retrieved papers, and decided on the inclusion of studies according to the inclusion and exclusion criteria listed below.

The inclusion criteria in the meta-analysis were as following: a). Cohort studies or nested casecontrol studies; b). Assessing the association between serum vitamin D levels and lung cancer risk or the association between vitamin D intake and lung cancer risk; c) The outcomes were lung cancer incidence or mortality; d). Reporting relative risk (RR) with 95\% confidence intervals (95\% CI) or other data to calculate risk estimates. Case-control studies, reviews, case-only studies, case reports, and editorials were all excluded. When several articles reported the results from the same participants, only the study with the largest sample of subjects was used into the meta-analysis.

\section{Data extraction}

A standardized protocol for data collection was used for data extraction. For each study we extracted information on first author, publication year, study design, country of participants, number of participants, gender distribution, mean age at enrolment, exact definition of dietary intake of vitamin $\mathrm{D}$, types of serum vitamin D levels, duration of follow-up, cases of incident lung cancer, risk estimates for lung cancer risk, and variables used for adjustment. Two authors performed the data extraction independently, and any initial disagreement was resolved by consensus after further review of the studies. The quality assessment of the included studies was conducted using the Newcastle-Ottawa Scale [20]. By the Newcastle-Ottawa Scale, there were four stars for participants' selection, two stars for study comparability, and three stars for outcomes. Studies with 6 or more stars were high quality studies.

\section{Statistical analysis}

The summary RR with 95\% CI was used to assess lung cancer risk. The Z test was used to estimate the statistical significance of pooled RR. The RR comparing high levels of vitamin D with low levels of vitamin D was used in the meta-analysis. For RRs comparing low levels of vitamin D with high levels of vitamin D provided in some studies, we transformed them into RRs comparing high levels of vitamin D with low levels of vitamin D. Between-study heterogeneity was assessed using Cochrane's Q test, and P value less than 0.05 indicated that there was obvious heterogeneity in the included studies [21]. A further measure of heterogeneity was assessed by $\mathrm{I}^{2}$ statistic method, and an $\mathrm{I}^{2}$ less than $50 \%$ was generally considered an acceptable level of variability [22]. When there was obvious heterogeneity, a random effect model was used to calculate the pooled RR [23]. When there was no obvious heterogeneity in the included studies, a fixed effect model was used to calculate the pooled RR [24]. Subgroup analysis was performed by the type 
Table 1. Main features of included studies on the association between vitamin D and lung cancer risk

\begin{tabular}{|c|c|c|c|c|c|c|}
\hline Study & Study design & Participants number & Gender & Cases & $\begin{array}{c}\text { Vitamin } \\
\text { D }\end{array}$ & Data type \\
\hline Giovannucci 2006 [19] & Prospective cohort & 47800 individuals & Men & 418 & Serum & $\begin{array}{l}\text { Increment per } 25 \\
\mathrm{nmol} / \mathrm{L}\end{array}$ \\
\hline Kilkkinen A 2008 [18] & Prospective cohort & 6937 individuals & Mixed & 122 & Serum & H vs L \\
\hline Freedman 2010 [17] & Prospective cohort & 16819 individuals & Mixed & 252 & Serum & H vs L \\
\hline Weinstein SJ 2011 [16] & Nested case-control & 29133 individuals & Men & 500 & Serum & $\mathrm{H}$ vs $\mathrm{L}$ \\
\hline Cheng 2012 [15] & Prospective cohort & 16693 individuals & Mixed & 258 & Serum & H vs L \\
\hline Afzal $2013[14]$ & Prospective cohort & 9791 individuals & Mixed & 507 & Serum & $50 \%$ increment \\
\hline Ordonez-Mena 2013 [13] & Prospective cohort & 9949 individuals & Mixed & 136 & Serum & H vs $\mathrm{L}$ \\
\hline Cheng 2013 [26] & Prospective cohort & 128779 individuals & Women & 1771 & Intake & $\mathrm{H}$ vs $\mathrm{L}$ \\
\hline Cheng 2014 [12] & Nested case-control & 1428 individuals & Mixed & 749 & Intake & $\mathrm{H}$ vs $\mathrm{L}$ \\
\hline Wong YY 2014 [28] & Prospective cohort & 4208 individuals & Men & 101 & Serum & H vs $L$ \\
\hline Skaaby 2014 [11] & Prospective cohort & 12204 individuals & Mixed & 110 & Serum & H vs $L$ \\
\hline Redaniel 2014 [27] & Nested case-control & 5037 individuals & Women & 484 & Intake & $\mathrm{H}$ vs $\mathrm{L}$ \\
\hline
\end{tabular}

Fig. 1. Forest plot showing an inverse association between vitamin D status and lung cancer risk.

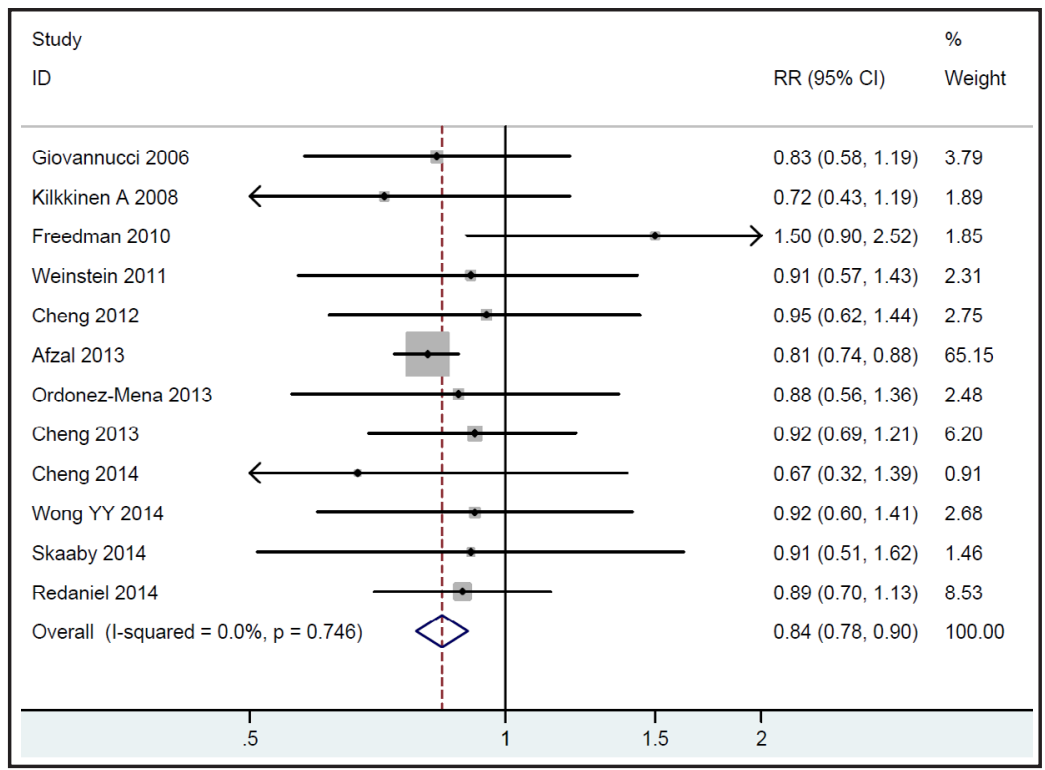

of vitamin D status (Serum vitamin D levels, or vitamin D intake). Sensitivity analysis was conducted by omitting one study by turns to evaluate the validity and reliability of the pooled RRs. Publication bias was evaluated graphically with the funnel plot, and asymmetry in the funnel plot suggested possible risk of publication bias. Egger's test was also employed to assess risk of publication bias in the meta-analysis [25]. All the statistical analyses were performed using STATA software (version 12.0).

\section{Results}

\section{Study selection and features}

A total of 453 abstracts of possible studies were identified from online databases. After an initial screening of retrieved abstracts, 14 papers were preliminarily considered for inclusion in the meta-analysis [11-19, 26-30]. After applying inclusion criteria, two papers were further excluded [29, 30], and 12 studies were finally included into the meta-analysis [11-19, 26-28]. Among those 12 studies, 9 studies were prospective cohort studies [11, 13$15,17-19,26,28]$, and 3 were nested case-control studies [12, 16, 27]. The main features of those 12 studies were shown in the Table 1 (Table 1). Those 12 studies were published from 2006 to 2014 (Table 1). All studies provided adjusted risk estimates of lung cancer according to the levels of vitamin D. Nine studies assessed the association between serum vitamin D levels and lung cancer risk, and three studies assessed the association between vitamin D intake and lung cancer risk (Table 1). According to the quality scale, all 12 studies had 6 or more stars and had high quality. 
Fig. 2. Forest plot showing the association of serum vitamin D levels and dietary vitamin D intake with lung cancer risk.

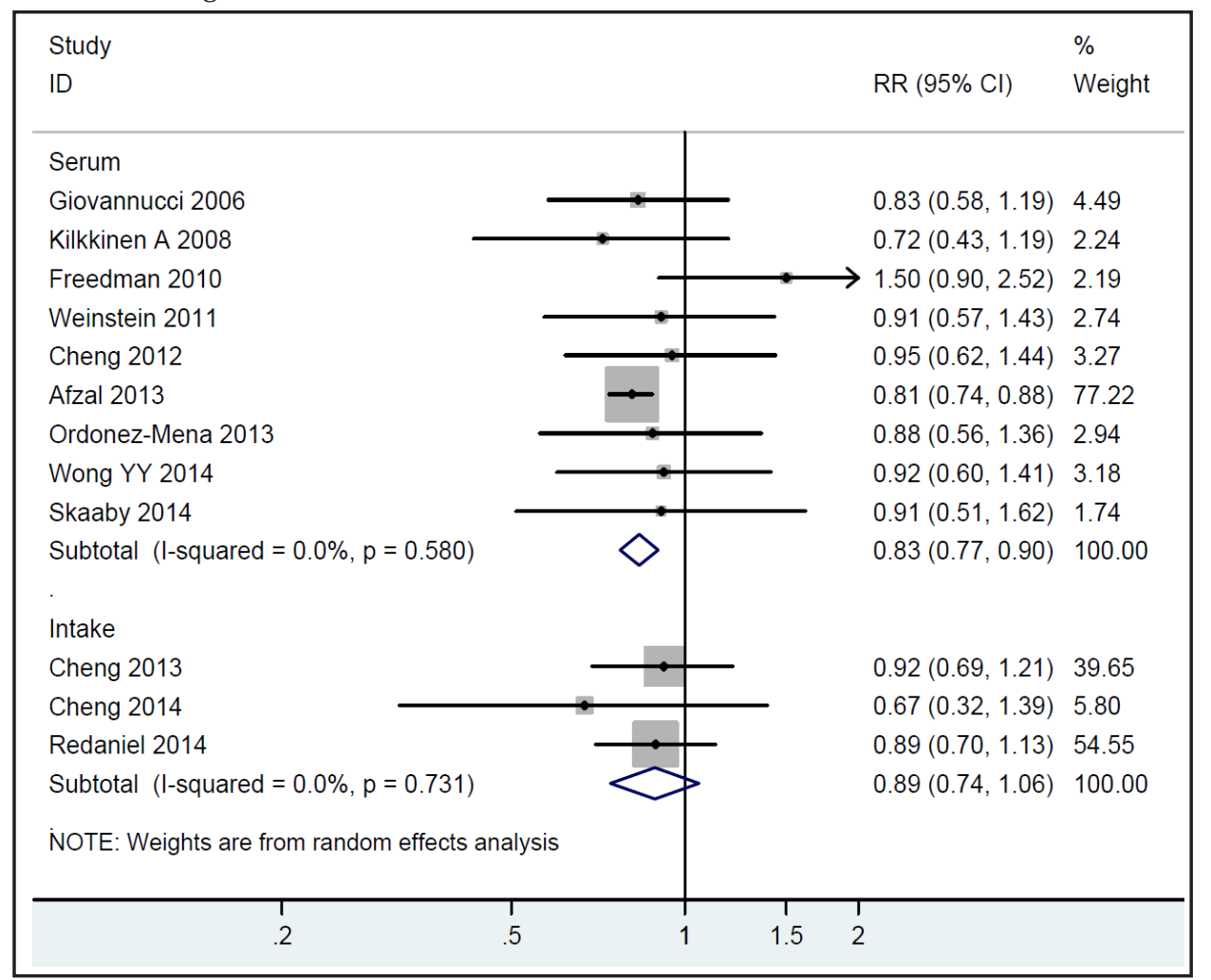

Fig. 3. Forest plot for the assessment of publication bias in the meta-analysis.

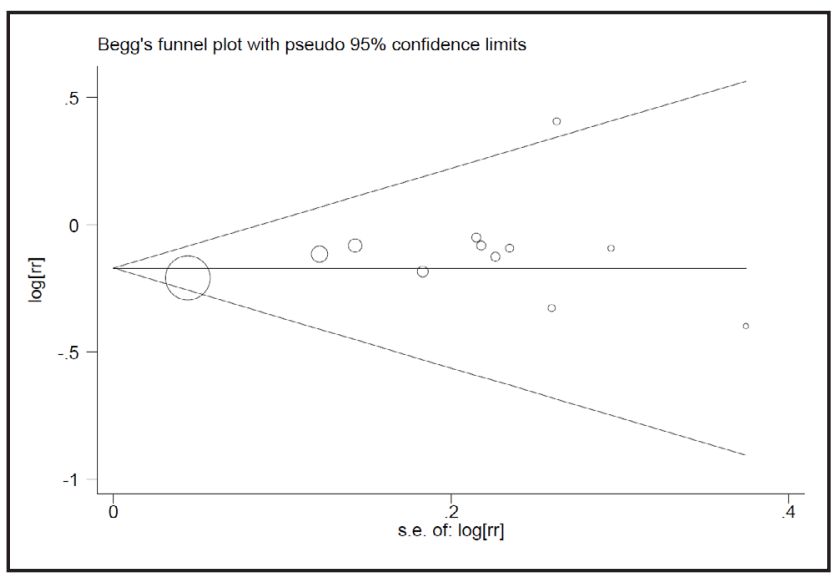

Meta-analysis

There was no between-study heterogeneity among those 12 studies $\left(\mathrm{I}^{2}=0.0 \%\right)$. Metaanalysis of total 12 studies showed that RR for the association of high vitamin D status with lung cancer was 0.84 (95\%CI 0.78-0.90, P < 0.001) (Fig. 1). Sensitivity analyses showed that no study had significant influence on the summary results. The RR of lung cancer for the highest versus lowest quintile of serum vitamin D levels was 0.83 (95\%CI 0.77-0.90, P < 0.001 ) (Fig. 2). The RR of lung cancer for the highest versus lowest quintile of vitamin $D$ intake was 0.89 (95\%CI 0.74-1.06, $\mathrm{P}=0.184$ ) (Fig. 2).

The funnel plot in the meta-analysis was symmetric, which suggested no obvious risk of publication bias. In addition, there was also no indication for publication bias in the Egger's test $(\mathrm{P}=0.12)$. 


\section{Cellular Physiology Cell Physiol Biochem 2015;36:299-305 \begin{tabular}{l|l} 
and Biochemistry Published online: May 04, 2015 & $\begin{array}{l}\text { DO 2015 S. Karger AG, Basel } \\
\text { www.karger.com/cpb }\end{array}$ \\
\hline
\end{tabular} \\ Zhang et al.: Vitamin D in Lung Tumor}

\section{Discussion}

Vitamin D has been suggested to be associated with risks of many diseases, such as diabetes [31-33]. Vitamin D has been suggested to have important roles against cancer development, and it has anti-tumor effects. Previous studies have provided strong evidence for the preventive effects of vitamin D against colorectal cancer and breast cancer [34]. However, there was no evidence for the preventive effects of vitamin D against other types of cancers, such as lung cancer. In present meta-analysis, we performed a meta-analysis of 12 studies involving a total of 288,778 individuals, which provided a comprehensive assessment of the role of vitamin D against lung cancer. Meta-analysis of total 12 studies showed that high vitamin D status was associated with decreased risk of lung cancer (Fig. 1). Subgroup analysis showed that high serum vitamin D level was associated with decreased risk of lung cancer, but high vitamin D intake was not associated with decreased risk of lung cancer (Fig. 2). Thus, current data suggest an inverse association between serum vitamin $D$ and lung cancer risk, and vitamin D has preventive effects against lung cancer.

Vitamin $\mathrm{D}$ also has been suggested to have important roles in cancer development, and it has anti-tumor effects [6, 7]. Findings from previous studies have showed that vitamin D can result in an additive decrease in cell proliferation and the induction of apoptosis in small cell lung carcinoma cell lines [7, 9]. Vitamin D can also inhibit the metastatic growth of lung cancer cells in animal models $[6,10]$. In addition, vitamin D also has the ability to prevent angiogenesis and migration in malignant cells. Thus, there are experimental explanations for the preventive role of vitamin D against lung cancer, and vitamin D could play an important role in several common pathways of cancer.

There are also many studies assessing the association between circulating levels of vitamin $\mathrm{D}$ and the prognosis of cancer patients $[35,36]$. Previous studies also provided some evidence for the prognostic roles of serum vitamin D levels in colorectal cancer and breast cancer [35, 37]. Several studies were also published to assess the association between serum vitamin $\mathrm{D}$ levels and prognosis of lung cancer patients, but they failed to identify a consistent conclusion [38-42]. More future studies are needed to further assess the association between serum vitamin D levels and prognosis of lung cancer patients.

In present meta-analysis, there were only three studies assessing the association between vitamin $\mathrm{D}$ intake and lung cancer risk. The RR for the highest versus lowest quintile of vitamin D intake was $0.89(95 \% \mathrm{CI} 0.74-1.06, \mathrm{P}=0.184)$ in present meta-analysis. Though there was not a statistically significant association found in the meta-analysis, there was a tendency of low risk of lung cancer in individuals with high levels of vitamin D intake. Thus, more studies are needed to investigate the effect of vitamin D intake on lung cancer risk.

Previous studies showed that vitamin D supplementation could decrease cancer mortality [43]. However, there is still no evidence for the lung cancer prevention by vitamin D supplementation from clinical trials. In addition, the adequate dosages and duration of vitamin D supplementation are also still unclear. Therefore, further clinical trials ware needed to evaluate whether vitamin D supplementation can prevent lung cancer. In addition, more trials on vitamin D supplementation are also needed to assess the benefits and harms among people with low vitamin D status, and assess the benefits and harms of longer duration of treatments or higher dosages of vitamin D.

In conclusion, current data suggest an inverse association between serum vitamin D and lung cancer risk. Further studies are needed to investigate the effect of vitamin D intake on lung cancer risk and to evaluate whether vitamin D supplementation can prevent lung cancer. In addition, more future studies are needed to further assess the association between serum vitamin D levels and prognosis of lung cancer patients.

\section{Disclosure Statement}

None declared. 


\section{Cellular Physiology Cell Physiol Biochem 2015;36:299-305 \begin{tabular}{l|l|l} 
DOI: 10.1159/000374072 & (C) 2015 S. Karger AG, Basel
\end{tabular} \\ Zhang et al.: Vitamin D in Lung Tumor}

\section{Acknowledgements}

We thanks all the helps provided by the authors of included studies.

\section{References}

1 Bolland MJ, Grey A, Gamble GD, Reid IR: The effect of vitamin d supplementation on skeletal, vascular, or cancer outcomes: A trial sequential meta-analysis. Lancet Diabetes Endocrinol 2014;2:307-320.

2 Mora JR, Iwata M, von Andrian UH: Vitamin effects on the immune system: Vitamins a and d take centre stage. Nat Rev Immunol 2008;8:685-698.

3 Chishimba L, Thickett DR, Stockley RA, Wood AM: The vitamin d axis in the lung: A key role for vitamin d-binding protein. Thorax 2010;65:456-462.

4 Moukayed M, Grant WB: Molecular link between vitamin d and cancer prevention. Nutrients 2013;5:39934021.

5 Pludowski P, Holick MF, Pilz S, Wagner CL, Hollis BW, Grant WB, Shoenfeld Y, Lerchbaum E, Llewellyn DJ, Kienreich K, Soni M: Vitamin d effects on musculoskeletal health, immunity, autoimmunity, cardiovascular disease, cancer, fertility, pregnancy, dementia and mortality-a review of recent evidence. Autoimmun Rev 2013;12:976-989.

6 Nakagawa K, Kawaura A, Kato S, Takeda E, Okano T: 1 alpha,25-dihydroxyvitamin d(3) is a preventive factor in the metastasis of lung cancer. Carcinogenesis 2005;26:429-440.

7 Mernitz H, Smith DE, Wood RJ, Russell RM, Wang XD: Inhibition of lung carcinogenesis by 1alpha,25dihydroxyvitamin $\mathrm{d} 3$ and 9-cis retinoic acid in the a/j mouse model: Evidence of retinoid mitigation of vitamin d toxicity. Int J Cancer 2007;120:1402-1409.

8 Feldman D, Krishnan AV, Swami S, Giovannucci E, Feldman BJ: The role of vitamin d in reducing cancer risk and progression. Nat Rev Cancer 2014;14:342-357.

9 Guzey M, Sattler C, DeLuca HF: Combinational effects of vitamin d3 and retinoic acid (all trans and 9 cis) on proliferation, differentiation, and programmed cell death in two small cell lung carcinoma cell lines. Biochem Biophys Res Commun 1998;249:735-744.

10 Nakagawa K, Sasaki Y, Kato S, Kubodera N, Okano T: 22-oxa-1alpha,25-dihydroxyvitamin d3 inhibits metastasis and angiogenesis in lung cancer. Carcinogenesis 2005;26:1044-1054.

11 Skaaby T, Husemoen LL, Thuesen BH, Pisinger C, Jorgensen T, Roswall N, Larsen SC, Linneberg A: Prospective population-based study of the association between serum 25-hydroxyvitamin-d levels and the incidence of specific types of cancer. Cancer Epidemiol Biomarkers Prev 2014;23:1220-1229.

12 Cheng TY, Goodman GE, Thornquist MD, Barnett MJ, Beresford SA, LaCroix AZ, Zheng Y, Neuhouser ML: Estimated intake of vitamin $d$ and its interaction with vitamin a on lung cancer risk among smokers. Int J Cancer 2014;135:2135-2145.

13 Ordonez-Mena JM, Schottker B, Haug U, Muller H, Kohrle J, Schomburg L, Holleczek B, Brenner H: Serum 25-hydroxyvitamin d and cancer risk in older adults: Results from a large german prospective cohort study. Cancer Epidemiol Biomarkers Prev 2013;22:905-916.

14 Afzal S, Bojesen SE, Nordestgaard BG: Low plasma 25-hydroxyvitamin d and risk of tobacco-related cancer. Clin Chem 2013;59:771-780.

15 Cheng TY, Neuhouser ML: Serum 25-hydroxyvitamin d, vitamin a, and lung cancer mortality in the us population: A potential nutrient-nutrient interaction. Cancer Causes Control 2012;23:1557-1565.

16 Weinstein SJ, Yu K, Horst RL, Parisi D, Virtamo J, Albanes D: Serum 25-hydroxyvitamin d and risk of lung cancer in male smokers: A nested case-control study. PLoS One 2011;6:e20796.

17 Freedman DM, Looker AC, Abnet CC, Linet MS, Graubard BI: Serum 25-hydroxyvitamin d and cancer mortality in the nhanes iii study (1988-2006). Cancer Res 2010;70:8587-8597.

18 Kilkkinen A, Knekt P, Heliovaara M, Rissanen H, Marniemi J, Hakulinen T, Aromaa A: Vitamin d status and the risk of lung cancer: A cohort study in finland. Cancer Epidemiol Biomarkers Prev 2008;17:3274-3278.

19 Giovannucci E, Liu Y, Rimm EB, Hollis BW, Fuchs CS, Stampfer MJ, Willett WC: Prospective study of predictors of vitamin d status and cancer incidence and mortality in men. J Natl Cancer Inst 2006;98:451459.

20 Wells G, Shea B, O'connell D, Peterson J, Welch V, Losos M, Tugwell P: The newcastle-ottawa scale (nos) for assessing the quality of nonrandomised studies in meta-analyses. Ottawa Health Research Institute Web site, 2014,

21 Cochran WG: The combination of estimates from different experiments. Biometrics 1954;10:101-129. 


\section{Cellular Physiology Cell Physiol Biochem 2015;36:299-305 \begin{tabular}{l|l|l} 
DOI: 10.1159/000374072 & (C) 2015 S. Karger AG, Basel
\end{tabular} \\ Zhang et al.: Vitamin D in Lung Tumor}

22 Higgins JP, Thompson SG, Deeks JJ, Altman DG: Measuring inconsistency in meta-analyses. BMJ 2003;327:557-560.

23 DerSimonian R, Laird N: Meta-analysis in clinical trials. Control Clin Trials 1986;7:177-188.

24 Mantel N, Haenszel W: Statistical aspects of the analysis of data from retrospective studies of disease. J Natl Cancer Inst 1959;22:719-748.

25 Egger M, Davey Smith G, Schneider M, Minder C: Bias in meta-analysis detected by a simple, graphical test. BMJ 1997;315:629-634.

26 Cheng TY, Lacroix AZ, Beresford SA, Goodman GE, Thornquist MD, Zheng Y, Chlebowski RT, Ho GY, Neuhouser ML: Vitamin d intake and lung cancer risk in the women's health initiative. Am J Clin Nutr 2013;98:1002-1011.

27 Redaniel MT, Gardner MP, Martin RM, Jeffreys M: The association of vitamin d supplementation with the risk of cancer in postmenopausal women. Cancer Causes Control 2014;25:267-271.

28 Wong YY, Hyde Z, McCaul KA, Yeap BB, Golledge J, Hankey GJ, Flicker L: In older men, lower plasma 25-hydroxyvitamin d is associated with reduced incidence of prostate, but not colorectal or lung cancer. PLoS One 2014;9:e99954.

29 Takata Y, Shu XO, Yang G, Li H, Dai Q Gao J, Cai Q Gao YT, Zheng W: Calcium intake and lung cancer risk among female nonsmokers: A report from the shanghai women's health study. Cancer Epidemiol Biomarkers Prev 2013;22:50-57.

30 Ananthakrishnan AN, Cheng SC, Cai T, Cagan A, Gainer VS, Szolovits P, Shaw SY, Churchill S, Karlson EW, Murphy SN, Kohane I, Liao KP: Association between reduced plasma 25-hydroxy vitamin d and increased risk of cancer in patients with inflammatory bowel diseases. Clin Gastroenterol Hepatol 2014;12:821-827.

31 Afzal S, Brondum-Jacobsen P, Bojesen SE, Nordestgaard BG: Vitamin d concentration, obesity, and risk of diabetes: A mendelian randomisation study. Lancet Diabetes Endocrinol 2014;2:298-306.

32 Bolland MJ, Grey A, Gamble GD, Reid IR: Vitamin d supplementation and falls: A trial sequential metaanalysis. Lancet Diabetes Endocrinol 2014;2:573-580.

33 Autier P, Boniol M, Pizot C, Mullie P: Vitamin d status and ill health: A systematic review. Lancet Diabetes Endocrinol 2014;2:76-89.

34 Gandini S, Boniol M, Haukka J, Byrnes G, Cox B, Sneyd MJ, Mullie P, Autier P: Meta-analysis of observational studies of serum 25-hydroxyvitamin d levels and colorectal, breast and prostate cancer and colorectal adenoma. Int J Cancer 2011;128:1414-1424.

35 Li M, Chen P, Li J, Chu R, Xie D, Wang H: Review: The impacts of circulating 25-hydroxyvitamin d levels on cancer patient outcomes: A systematic review and meta-analysis. J Clin Endocrinol Metab 2014;99:23272336.

36 Wang B, Jing Z, Li C, Xu S, Wang Y: Blood 25-hydroxyvitamin d levels and overall mortality in patients with colorectal cancer: A dose-response meta-analysis. Eur J Cancer 2014;50:2173-2175.

37 Buttigliero C, Monagheddu C, Petroni P, Saini A, Dogliotti L, Ciccone G, Berruti A: Prognostic role of vitamin $\mathrm{d}$ status and efficacy of vitamin d supplementation in cancer patients: A systematic review. Oncologist 2011;16:1215-1227.

38 Tretli S, Schwartz GG, Torjesen PA, Robsahm TE: Serum levels of 25-hydroxyvitamin d and survival in norwegian patients with cancer of breast, colon, lung, and lymphoma: A population-based study. Cancer Causes Control 2012;23:363-370.

39 Zhou W, Suk R, Liu G, Park S, Neuberg DS, Wain JC, Lynch TJ, Giovannucci E, Christiani DC: Vitamin d is associated with improved survival in early-stage non-small cell lung cancer patients. Cancer Epidemiol Biomarkers Prev 2005;14:2303-2309.

40 Liu Y, Chen W, Hu ZB, Xu L, Shu YQ Pan SY, Dai JC, Jin GF, Ma HX, Shen HB: Plasma vitamin d levels and vitamin $\mathrm{d}$ receptor polymorphisms are associated with survival of non-small cell lung cancer. Chin J Cancer Res 2011;23:33-37.

41 Heist RS, Zhou W, Wang Z, Liu G, Neuberg D, Su L, Asomaning K, Hollis BW, Lynch TJ, Wain JC, Giovannucci E, Christiani DC: Circulating 25-hydroxyvitamin d, vdr polymorphisms, and survival in advanced non-smallcell lung cancer. J Clin Oncol 2008;26:5596-5602.

42 Zhou W, Heist RS, Liu G, Asomaning K, Neuberg DS, Hollis BW, Wain JC, Lynch TJ, Giovannucci E, Su L, Christiani DC: Circulating 25-hydroxyvitamin d levels predict survival in early-stage non-small-cell lung cancer patients. J Clin Oncol 2007;25:479-485.

43 43. Bjelakovic G1, Gluud LL, Nikolova D, Whitfield K, Krstic G, Wetterslev J, Gluud C. Vitamin D supplementation for prevention of cancer in adults.Cochrane Database Syst Rev. 2014;6:CD007469. 